\title{
Efficient Deployment of Lightning and Surge protection Schemes in Nigeria Petroleum Industry Facilities
}

\author{
Isdore Onyema Akwukwaegbu*1, Chisom Patrick Mbachu², Nsan-Awaji Peterson Ene-Nte ${ }^{2}$ \\ ${ }^{l}$ Department of Electrical /Electronic Engineering, Faculty of Engineering, Federal University of Technology, Owerri, Nigeria. \\ ${ }^{2}$ Department of Electrical /Electronic Engineering, Federal University of Technology, Owerri, Nigeria. \\ *Corresponding Author: Isdore Onyema Akwukwaegbu, Department of Electrical /Electronic Engineering, Federal University of \\ Technology, P.M.B. 1526, Owerri Imo state, Nigeria. Email: isdoreonyema@gmail.com
}

DOI: $10.31364 /$ SCIRJ/v8.i12.2020.P1220832

http://dx.doi.org/10.31364/SCIRJ/v8.i12.2020.P1220832

\begin{abstract}
The petroleum industry is located in one of the most active lightning zones in the world with a keraunic level of about 140 lightning days per year. In the past, lightning strikes have reportedly caused severe damages to the petroleum industry's facilities, control and communication equipments, etc. This Paper therefore evaluates available types of lightning and surge protection systems and proposes the best system or combination of systems for the Nigeria petroleum industry; which will utilize Charge Transfer Technology known as Dissipated Array System (DAS) developed by Lightning Eliminators Consultants (LEC), with all connections linked to earth grid. Proposed in this paper, is the installation of effective surge protection scheme, to minimize secondary effects of lightning strikes on the electrical systems by equipping such systems with metal oxide surge arrestors and installation of effective surge protection scheme on both ends (input/output) of instrumentation cables and protecting all data, communication and electronic control circuits with multi-element surge suppression devices. All the main power, control and communication feeders to the facility and office complexes should be protected by the effective coordinated installation of lightning arrestors, transient voltage suppressors(TVSS) as well as Power Distribution Supplies(PDS)/ Uninterrupted Power Supplies(UPS) units for major facilities such as the control and communication. The deployment of combination of options $a, b, c$ and $d$ surge protection systems at transformer high voltage connections, process control, firel gas and safeguarding systems, communications circuits and panel board feeders supplying sensitive electronic loads would eventually provide greater advantageous results.
\end{abstract}

Keywords: Lightning and Surge Protection, Dissipated Array Systems, Franklin Rod

\section{Introduction}

The petroleum industry's history provides ample evidence of the destructive nature of lightning activity and the resulting fires. Millions of dollars of petrochemical products and facilities are destroyed each year by lightning-related phenomena in the petroleum industry. Each year, lives are lost as the direct result of being in proximity to these facilities when they are ignited or exploded due to effects of lightning strikes. According to study performed on 480 tank fire incidents, about 33\% of all tank fires were caused by lightning strikes [1]. Sixteen oil companies sponsored a study to discover the cause of tank fires; the study concluded that lightning is the most common cause of about $95 \%$ of rim seal fires [2].It is true that the risk of losing one tank of product is small, but it is also true that preventing the loss of one tank and its contents in a given country will usually pay for the entire protection of the petroleum storage facilities in that country [3].

The existing lightning protection system in the petroleum industry is the conventional (Franklin rods) approach that consists of rods (type and material not carefully chosen) at the top of some buildings and structures, with wire connections to the earth rods. The wire connection between the rods and earth are usually not checked from time to time. If these connections are corroded in any way, the impedance between the rods and the earth is increased and the effectiveness of the scheme is diminished. As a matter of fact, an improperly designed system can even aggravate lightning-related problems [4].

A typical example of the foregoing is seen from the Nigerian fire of 1993 where a 670,000 barrel tank was set on fire by lightning. Both the tank and its entire content of light crude were destroyed. The conventional radio-active lightning protection system installed on this tank did not prevent the fire. The communication system has been disrupted several times by direct lightning strikes on the tower.

www.scirj.org

(C) 2020, Scientific Research Journal

http://dx.doi.org/10.31364/SCIRJ/v8.i12.2020.P1220832

This publication is licensed under Creative Commons Attribution CC BY. 


\section{Theory of Lightning Strike}

In a thunderstorm, a charged cloud develops a very strong electrostatic potential, which also induces a charge on earth of equal but opposition potential. This charge may be considered as an electrical shadow as shown in Figure 1; and as the charged cloud moves, so does the electrical shadow. This shadow induces an electrical charge on everything within its sphere of influence. This includes flammable liquids in their storage containers (the bond charge). The charge within the cloud is due to a surplus of electrons within the base of the cloud [5]. The charge on the earth (the shadow charge) beneath the cloud is equal but opposite. This means, there is a localized deficiency of electrons in the earth beneath the cloud.

When the charge within the cloud reaches a critical level, the resulting potential causes the air beneath the cloud to ionize, forming paths called "step leaders" as presented in Figure 2. As the step leaders move towards earth, upward streamers develop, which reach toward the step leaders. When the step leader makes contact with an upward streamer, the circuit is closed and "Charge Neutralization" occurs. Charge neutralization is the process of transferring electrons from the surplus body (the cloud) to the area with the deficiency (the earth under the cloud) as presented in Figure 3. This direct strike typically discharges thousands of Amperes at potentials of millions of Volts in a few millionths of a second. The radius of the actual strike zone of the lightning discharge is between 10 and 100 meters. However, the area of the storm cell may be 15 to 150 Square kilometers at its base. This means that the area that accumulates a charge is much greater than that affected by the strike[6].

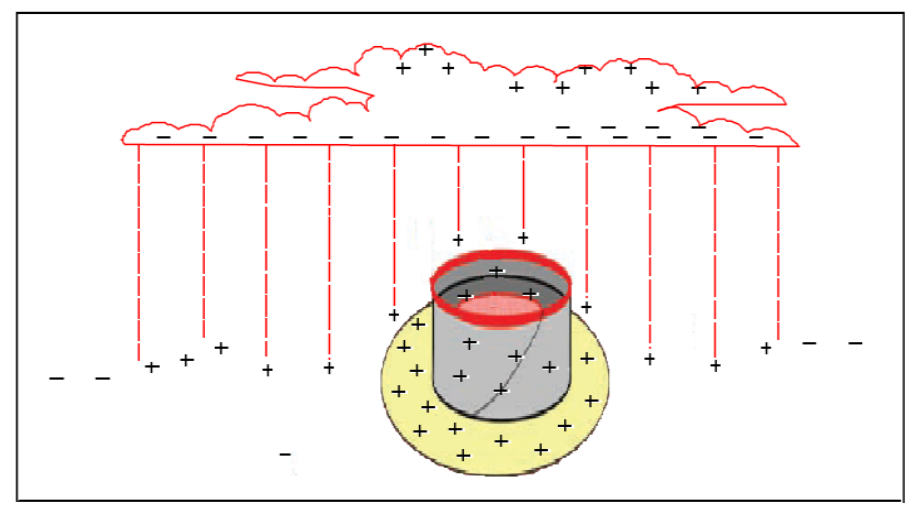

Figure 1: The Charged Cloud Phenomenon

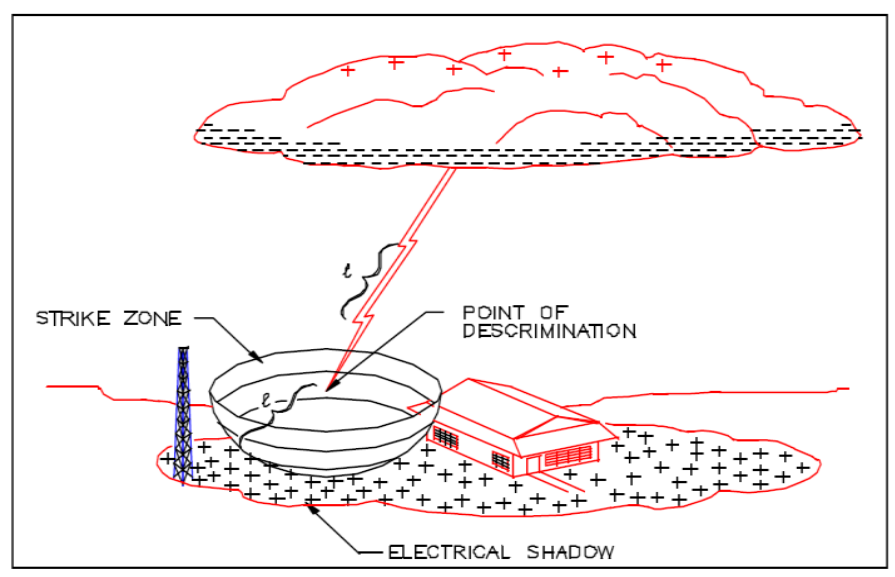

Figure2: Strike Zone Configuration

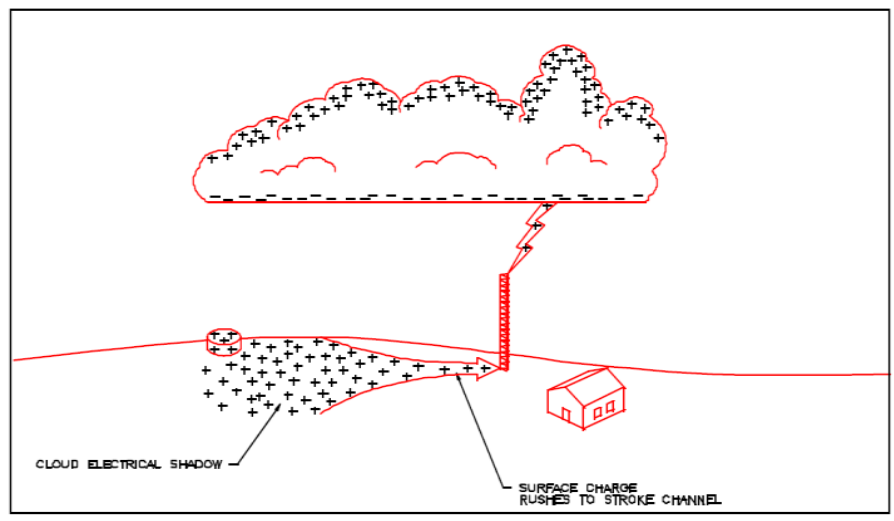

Figure 3: The Charge Neutralization Process, After Strike

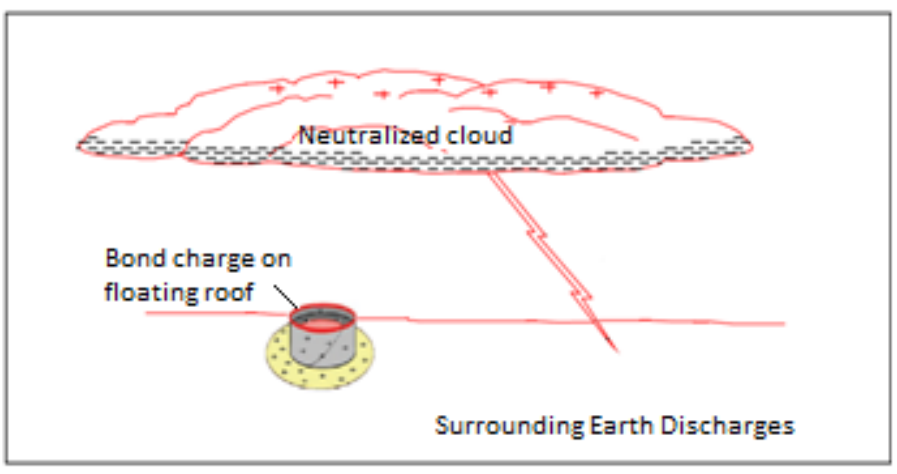

Figure 4: Bound Charge Hazard.

\subsection{Effects of Lightning}

There are two main effects of a lightning strike- the direct effects of a strike, and the secondary effects. The direct strike is a rapid discharge of high electrical currents at high voltages. The high current causes air and matter to ionize due to the heat created by the passage of the discharge. This heat and the electric 
current often cause fires and may melt metals along which the current flows. The effects of the high voltage and current usually incinerate unprotected electronic components. In addition to the hazard created by the direct lightning strike, there are secondary effects such as: bound charge, earth currents, electromagnetic and electrostatic pulses. Each of these secondary effects may create transient voltages, which may initiate fires or damage equipments.

The storm cell induces a charge in everything beneath it. Since petroleum products are generally stored in metallic containers (which are conductors), the container and contents are charged to the potential of the local earth. Prior to a lightning strike, the tank, the contents and the earth are all at the same potential. Typically, the fluid (crude oil) being stored, is a dielectric material, which means that even though it does not readily conduct electricity, it may have a stored charge (the Bound charge). Furthermore, since the fluid is an insulator, the charge stored in the fluid cannot change or dissipate rapidly. Experience at some petrochemical plants appears to indicate that following a rapid discharge of the stored charge on the vessel due to a nearby lightning strike, a large potential difference may exist between the fluid and vessel. This potential difference may lead to a secondary arc between the fluid and the vessel after the actual lightning strike, and a fire may result. Floating roof tanks which discharge gas from the seals are sensitive to rim fires. Since the area affected by the electrical field of the cloud is much larger than the area of the actual lightning strike (about 1000 times), a secondary arc in a tank caused by the bound charge would be possible rather than the actual lightning strike on the tank, as shown in Figure 4.

As lightning occurs, the high voltage and high current in the very short discharge time create very intense electrostatic and electromagnetic fields. Any power, control or communication conductor in the area will be induced with large transient voltage by these intense fields. The induced transient voltages then travel along the conductors to the peripheral equipment and may damage the power, control or communication equipment to which it is connected [7]. The charge induced in the earth by the "shadow" will create currents (called Earth currents) as the cloud moves. Discontinuities in the conductive medium (the earth and structures attached to the earth) may cause arcing at a conductor/non-conductor interface, which may also ignite flammable liquids if they are present.

The lightning strokes are predominantly of negative polarity. However, the surges on transmission lines can be of negative as well as positive polarity depending on whether they are caused by the direct lighting stroke or by induction. The percentages of positive polarity to total surges reported are: strokes to transmission lines 7 to $18 \%$, distribution lightning arrester surges $37 \%$, and station lightning arrester surges $12 \%$ [8].

The total duration of a lightning stroke is about one second or so. The peak current in the stroke may range from 1kA to 200kA. The actual current in the stroke depends on the terminating impedance and the surge impedance of the lightning channel. The time to first peak and the time to half value on the tail have values between 0 to $10 \mu$ s and 5 to $90 \mu$ s respectively. About $50 \%$ of stroke currents have a rate of rise exceeding $7.5 \mathrm{kA} / \mu \mathrm{s}$ and $10 \%$ exceed $25 \mathrm{kA} / \mu \mathrm{s}$. The mean duration of stroke current, above half value is $30 \mu$ s and $18 \%$ have longer half times than $50 \% \mu$ s [8].

\section{Analysis of Over Voltages due to Lightning}

Over-voltages due to lightning are generally confined to overhead transmission and distribution systems. These overvoltages occurred in petroleum industry's facilities due to indirect strokes and direct strokes.

I. Indirect Strokes: The negative charge on lower part of the cloud and the leader stroke induce positive charges on the ground, earth conductors and other grounded objects. Some of these positive charges flow to the phase conductors by leakages over insulators and through neutral points of transformers. A lightning discharge in the vicinity of the line will cause the field to collapse and the positive charge on the conductor to be released and initiate indirect lightning transients. The charges on the earth wire travel down to earth through the towers and those on the phase conductors travel along the conductors and are dissipated through corona and resistance loss. The induced surges are equal on all the three phases, usually of positive polarity and their wave front is typically $10 \mu \mathrm{s}$. The crest values depend on the stroke current, distance from the stroke, height of phase conductors and the presence of shield wires and rarely exceed $200 \mathrm{kV}$. Thus, the indirect strokes, while capable of producing flashover on $11 \mathrm{kV}$ lines, have little practical significance for lines of $33 \mathrm{kV}$ and higher operating voltages.

II. Direct Strokes: The over-voltages due to direct strokes can be very high and may cause flashovers. The simple equivalent circuit capable of analyzing the surges due to direct lightning stroke is shown in figure 5.

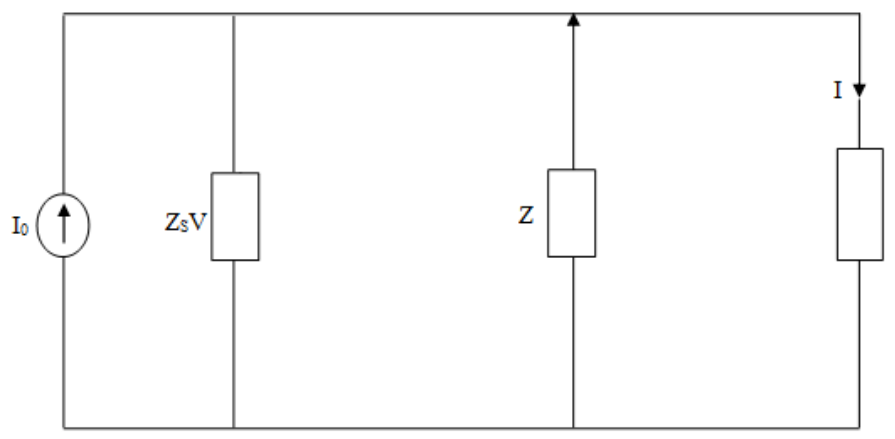

Figure5: simple equivalent circuit for analyzing the surges due to direct lightning stroke.

The voltage across the terminating impedance is determined as follows;

$$
V=I Z=\frac{I_{0} Z_{S} Z}{Z+Z_{S}}=\frac{I_{0} Z}{\left(1+\frac{Z}{Z_{S}}\right)}
$$

Where:

www.scirj.org

(C) 2020, Scientific Research Journal

http://dx.doi.org/10.31364/SCIRJ/v8.i12.2020.P1220832

This publication is licensed under Creative Commons Attribution CC BY. 
$\mathrm{I}_{0}=$ Stroke current to zero resistance earth.

$Z_{\mathrm{s}}=$ Surge impedance of stroke channel.

$\mathrm{Z}=$ Terminating impedance.

$\mathrm{I}=$ Current flowing into the terminating impedance.

$\mathrm{V}=$ Voltage across the terminating impedance.

Since $\mathrm{Z}$ is generally small relative to $\mathrm{Z}_{\mathrm{s}}$, the current I differs only very little from the stroke current to zero resistance earth (i.e., $\mathrm{I}_{0}$ ). The value of the terminating impedance depends on whether the direct stroke hits the phase conductor or the tower or the earth wire. This is father described as follows:

- Direct stroke-to-phase conductor: When a lightning stroke strikes a phase conductor, surges travel away from the point of strike in each direct. The terminating impedance is equal to half the surge impedance of the phase conductor. The conductor potential is determine by substituting $Z_{c} / 2$ for $\mathrm{Z}$ in equation (1) as follows:

$$
V=\frac{I_{0}\left(Z_{c / 2}\right)}{\left(1+\frac{Z_{c / 2}}{Z_{S}}\right)}
$$

If $Z_{c} / 2$ is small compared to $Z_{\mathrm{s}}$, the result is

$$
V=\frac{1}{2} I_{0} Z_{c}
$$

With the value of $Z_{c}$ as $400 \Omega$, a stroke current as low as $10 \mathrm{kA}$ has more than $65 \%$ probability of being exceeded, will cause a potential of about $2000 \mathrm{kV}$ as follows:

$$
\begin{aligned}
& V=\frac{1}{2}(40 \mathrm{kA})(400 \Omega) \\
& =2000 \mathrm{kV}
\end{aligned}
$$

This is a very high voltage and only the lines insulated from ultra high voltages can withstand this stress. Thus, a direct stroke to phase conductor will invariably lead to flashover. These adverse effects of direct strokes to phase conductors can be prevented by using one or two ground wires.

- Direct Stroke-to-tower: For a direct stroke-to-tower, the terminating impedance is the resultant of the tower surge impedance $Z_{\mathrm{f}}$ in parallel with half the ground wire surge impedance $Z_{\mathrm{g}}$. If the system has two ground wires in each direction, $Z_{g}$ should be taken as the equivalent surge impedance. The tower top voltage $\mathrm{V}_{\mathrm{t}}$ is determined by substituting the following value of $\mathrm{Z}$ in equation (1)

$$
\begin{aligned}
& Z=\frac{Z_{t}}{\left(1+\frac{2 Z_{t}}{Z_{g}}\right)} \\
& V_{t}=I Z=\frac{I Z_{t}}{\left(1+\frac{2 Z_{t}}{Z_{g}}\right)}=\frac{I_{0} Z}{\left(1+\frac{Z}{Z_{s}}\right)}
\end{aligned}
$$

When a lightning surge travels on a ground wire, the associated current and voltage waves induced in any parallel conductor become a surge of the same polarity and of $\mathrm{K}$ times the ground wire voltage, where $\mathrm{k}$ is the coupling factor between the phase conductor and the ground wire. The voltage stressing the tower insulation is the difference between the tower top potential and the voltage induced in the phase conductor presented as follows:

$$
V_{i}=(1-K) V_{t}=\frac{(1-K) I_{0} Z}{\left(1+\frac{Z}{Z_{S}}\right)}
$$

Where $\mathrm{V}_{\mathrm{i}}$ is the voltage stressing the tower insulation and $\mathrm{Z}$ is the terminating impedance as given in equation (4).

The coupling factor $\mathrm{K}$ generally lies between 0.15 and 0.3 . Thus, it is seen that the insulation stress is reduced considerably by the coupling effect. If the voltage $V_{i}$ exceeds the impulse strength of the insulator string, a back flashover from the tower to the phase conductor may occur.

- Direct Stroke-to-ground wire at mid span: A lightning stroke within a quarter span of a tower is considered equivalent to a stroke at the tower itself whereas a stroke within a quarter of the mid span is considered equivalent to a stroke to mid span.

When a lightning stroke hits the ground wire at mid-span, the voltage $\mathrm{V}_{\mathrm{m}}$ on the ground wire is determined by setting the terminating impedance equal to half the self surge impedance of the ground wire, i.e., $\mathrm{Z}=Z_{g} / 2$ from equation (1) as follows:

$$
V_{m}=\frac{I_{0} Z_{g}}{2\left(1+\frac{Z_{g}}{2 Z_{s}}\right)}
$$

The voltage on the phase conductor is $\mathrm{KV}_{\mathrm{m}}$. The voltage (1-K) $\mathrm{V}_{\mathrm{m}}$, which the air gap must withstand, is considerably higher than the voltage across the tower insulation strings caused by a stroke of equal intensity striking the tower. This is because of the fact that the terminating impedance in this case, (i.e., stroke to ground wire) is higher than that in the case of stroke to tower. For this reason, it is a usual practice to increase the mid - span clearance by sagging the ground wire less than the phase conductors. Assuming that there is no flashover at mid - span, the voltage waves $V_{m}$ and $K V_{m}$ travel on the ground wire and phase conductor respectively may cause flashover at the tower. Successive reflections from adjacent towers tend to decrease the voltage stressing the insulation $[8,9]$.

\section{Materials and Methods}

There are two basic methods of lightning protection that could be deployed for direct strikes protection. These include: (i) Conventional lightning protection system with rods (usually copper or copper clad steel) and conductors connected to earth (ground); (ii) Charge Transfer Technology (CTT) also known as the Dissipated Array System (DAS).

\subsection{Lightning protection scheme with rods and conductors connected to earth}

The conventional lightning protection technology (more commonly known as Lightning or Franklin rods) [10] is a system of lightning rods (of conducting metal, usually copper or copper clad steel) along the top of each tank, tower or building. Conductors are connected to the lightning rods and to copper clad steel rods driven into the earth around the structures to provide an earth connection. This technology was developed almost 200 
years ago and protects structures from fire caused by direct strikes by collecting the lightning strikes and conducting the current to earth rather than through the structure itself. The conventional method does provide some protection; but is not designed to eliminate lightning strikes. Sometimes, the conventional design provides a focal point where lightning will strike, and a connection to earth for the lightning current. Since this path is available, it protects equipment by providing a lower impedance path to earth, so nearby equipment is not usually damaged. This type of protection is effective in protecting structures or buildings that do not enclose flammable materials, or house central control or communication equipment.

\subsection{Early Streamer Emitter Technology}

Early Streamer Emitter Technology is another variation of the conventional approach. It provides protection by early attraction of the direct strike and conduction of the current to the earth grid by a low impedance path [11]. This type of protection is most effective for buildings and similar structures. Protection of communications and control equipment by surge suppression devices is still necessary.

\subsection{Charge Transfer Technology}

The Charge Transfer Technology, also known as the Dissipated Array System (DAS) technique of lightning protection is somewhat different from the conventional or early streamer emitter system. It relies on a very large array of multiple sharp points all connected to earth in protecting the tank, tower or structure. The points take electrons from the air leaving free ions. The ion flow increases with the strength of the field and with air movement. This ion flow dissipates the induced charge in the earth slowly and constantly throughout the duration of the storm. When large numbers of ions are produced, it becomes visible as corona or "St. Elmo's Fire". Ionization gives rise to a bluish light called St. Elmo's Fire. The result of this continuous discharge is that the areas is left relatively free of charge; and due to the low residual voltage, no direct strikes or secondary effects occur in the area protected by the Dissipated Array System.

While in some respects, the CTT or DAS design is a departure from the conventional design of lightning protection systems, the DAS does have a history of successful installations in petrochemical facilities situated within high lightning hazard areas. Prior to installation of the DAS, these facilities had an annual average of 4 to 25 outages per year due to lightning strikes. But after installation of DAS, there has been a history of no outages due to lightning over a period of 8 to 15 years. The DAS system provided by lightning Eliminators and consultants is the only effective Charge Transfer Technology, commercially available for the protection of tank farm facilities, control buildings and communication towers. Communication and control circuits should also be protected by surge suppression.

\subsection{Protection from Secondary Effects}

The conventional or early streamer emitter lightning protection design works well to protect from the direct effects of lightning strikes to certain pieces of equipment and facilities such as steel structures, switchyards and buildings. However, protection against the secondary effects, such as storage tanks where the fluid has a bound charge, or arcing due to earth current, requires a different approach. Some equipment may be damaged by the transient voltages created by the electromagnetic or electrostatic pulses, which attract direct strikes to the immediate area resulting to high transient voltages. Protection of electronic equipment from the transient voltages requires surge suppression of some sort on the circuits.

The Charge Transfer Technology relies on ion flow to dissipate the induced charge in the earth, slowly and constantly through the duration of the storm. The result of this continuous discharge is that the protected area is left relatively free of charge, and due to the low residential voltage, no direct strikes or secondary effects occur in the vicinity. This is effective in preventing arcing due to the bound charge or earth currents for storage tanks. With the elimination of direct strikes by the Charge Transfer Technology, the hazard of lightning induced transient voltages on electronic equipment is reduced. However, the electronic circuits still need to be protected by surge suppression to guide against transient voltages induced in the electrical system itself through faults and load switching or nearby lightning strikes to the unprotected zone.

\subsection{Surge Suppression}

Surges are generated in power systems by lightning or by switching operations that rapidly redistribute energy between inductance and capacitance [12]. Regardless of which type of lightning protection system is chosen, the power and electronic circuits will require surge suppression to protect against the secondary effects such as electromagnetic pulses or induced voltages due to nearby strikes. Figure 6 shows the protection methods base on the concept of volt-time characteristic. The scheme operates on dual modes to protect circuit against transients: (i) the series segment block the transients, terminating further propagation toward sensitive circuits. (ii) the parallel segment diverts transient, limiting residual voltages.

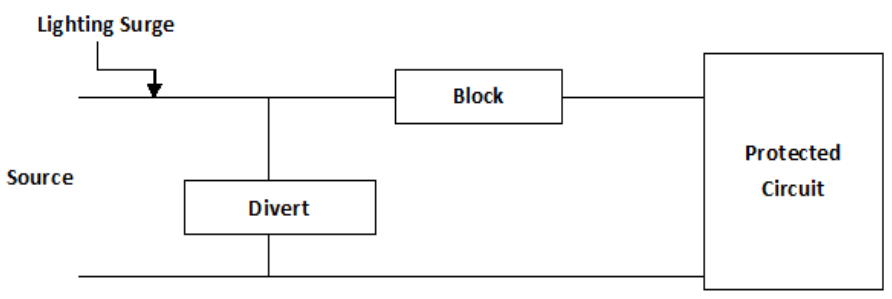

Figure 6: Protection methods

When dealing with arrant transients (Such as lightning strokes), the blocking of a transient may not always be possible; the diverting of the transient is more likely to find general 
application. This is better illustrated in the operation of a rodgap. Under normal circumstances the open gap represents a vary impedance, almost infested. When the gap flashes over, it switches on to a low impedance mode, for the voltage of the arc that forms are probably a few hundred volts only. The traditional means of providing surge suppressor is illustrated in Figure 7.

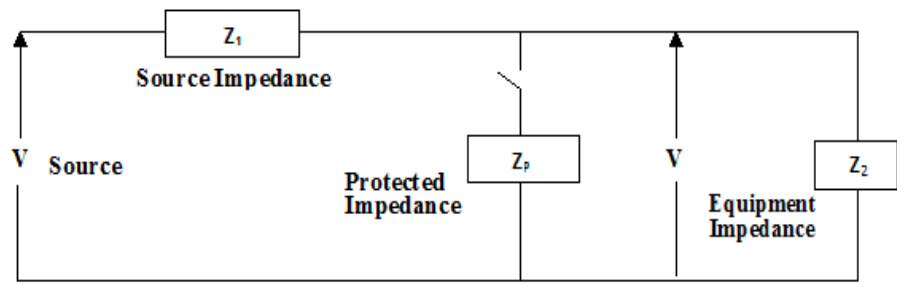

Figure 7: Impedance dividing effect of the protective device and system

Appling Thevenin's Theorem to Figure 6, the current flowing through the circuit when the switch is closed is given by

$$
I=\frac{V}{Z_{p}+{ }^{Z_{1} Z_{2}} /\left(Z_{1}+Z_{2}\right)}=\frac{\left(z_{p}+Z_{2}\right) V}{Z_{p} Z_{1}+Z_{p} Z_{2}+Z_{1} Z_{2}}
$$

Where $\mathrm{V}=$ voltage across the switch prior to closing.

$$
V_{1}=\frac{Z_{p}\left(Z_{1}+Z_{2}\right) V}{Z_{p} Z_{1}+Z_{p} Z_{2}+Z_{1} Z_{2}}
$$

For a surge suppressor to do a satisfactory job of protecting equipment represented by the impedance $Z_{2}$, neither the voltage $\mathrm{V}$, which is seen initially at the time switch closes, nor the voltage $\mathrm{V}$, should exceed the voltage that the equipment is capable of sustaining. There are three main types of surge suppression for low voltage and electronic circuit. These include: Varistors, Trans-sorbs (Back to Back Zener Diodes) and Gas Tube. Each type of surge protection has different characteristics in terms of peak cut-off (or let-through) voltage, response time, and energy or current limit. All surge suppression devices operate on the same basic principle of limiting the voltage between a given phase and earth potential [13]. A surge arrestor is connected between each phase conductor and earth. In normal operation, the surge arrestor acts like an insulator, and there is minimal current flow through the arrestor. When the voltage between phase and earth rises above the threshold voltage, the arrestor "insulator" breaks down; and current flows between the phase conductor and earth through the surge arrestor. The original surge arrestors were spark gap arrestors. When the voltage rose high enough, the voltage stress on the air gap would increase to the point where an arc would form, and the current would flow through the arc from the phase conductor to earth. This would limit the voltage and energy to components on the circuit downstream of the arrestor. Typically, surge arresters limit the over-voltage to a circuit to $200 \%$ of normal voltage. However, a voltage surge with at very steep wave-front may rise further before the surge arrestor has time to operate $[14,15,16]$.

\subsection{Common Protection Devices}

- Varistors are one of the most commonly used for protection from voltage surges on communication, power and electronic devices. Varistors clamp to the selected voltage in the sub-nano-second range. The voltage is somewhat dependent on the current flow, so there may be some overvoltage let through. To protect power feeders, the clamping voltage must be above the maximum operating voltage of the circuit, so some overvoltage will be experienced by the equipment. Since the varistor is a clamping device, it must be able to dissipate the energy of the current flowing through the device. For high energy dissipation requirements, several varistors must be used in parallel.

- Tran-sorbs (Back to Back Zener Diodes) are typically used as secondary protection devices due to their high speed and tight clamping characteristics. They are low power devices, and require suppression to dissipate the incoming energy. Tran-sorbs are typically used for highly sensitive equipment, such as Supervisory Control and Data Acquisition Systems (SCADA) and communications equipment.

- Gas tubes are primary protection devices, and were once the standard for protecting telecommunication circuits due to their high power capability. They relatively slow acting devices (in the order of 5 microseconds) and only effective for voltage surges when protecting equipment with high dielectric strength, such as analog telephone lines. When the gas tube fires, it effectively short circuits the conductor to earth, and therefore is not useful for protecting power feeders.

The most effective protection from voltage surges for sensitive lines such as power feeders to electronic, control and communications equipment would be a combination of a Varistor and Tran-sorbs. For less sensitive power feeders, aVaristor would provide adequate protection from voltage surges. For distribution and high voltage power circuits, the primary type of protection is supplied by either spark-gap or metal oxide surge arrestors. However, it has largely been replaced on power circuits by the metal oxide surge arrestor. The spark-gap surge arrestor is slower acting and has a higher let-through voltage than the metal oxide surge arrestors. For this reason, surge protection for power circuits is presently designed with metal oxide arrestors. The only place spark-gap arrestors are used is on high transmission lines where existing surge protection is provided by older spark-gap arrestors [17].

\section{Evaluation of various Lightning and Surge Protection Schemes}

The following lightning protection schemes could be deployed in Petroleum industry, overhead transmission and distribution circuits:

(a) Franklin Rods System: This scheme utilizes the installation of Franklin Rods on the storage tanks and all other facilities within the industry. The merit of the scheme include being economical, adequate for buildings and non-critical areas. 
While its drawback include exposing oil storage facilities to risk of bound charge and earth currents, tendency of Rod to attract charge, subjecting tanks to risk of experiencing more direct strikes and possible loss of communications due to direct hit or nearby lightning strikes and secondary effects.

(b) Early Streamer Emitter (ESE) System: The scheme when installed on the tanks and all other facilities in petroleum industries has same advantage as Franklin Rods Scheme.

(c) Dissipated Array Systems (DAS): The scheme involves the installation of DAS charge transfer technology type of lightning protection for all tanks, buildings and other petroleum industry facilities. The advantages of successful installation of the system include avoidance of strikes as well as secondary effects such as bound charge and earth currents and prevention of lightning - induced control and communication outages. It has disadvantages of being an expensive form of lightning protection and may not be required for non-critical areas and buildings.

(d) DAS and Franklin Rods Hybrid System. In this scheme, DAS are deployed for tanks, communication towers, control buildings, power plant and substations; while Franklin Rods system protects restaurant, offices, residential areas, workshops and storage areas. The advantages of the scheme include protection of oil storage tanks, communication and control system from direct strikes; effective protection coverage for critical facilities; minimal cost; while protection for secondary effects such as bound charge or earth currents is not needed for non-areas. Its disadvantages include being more expensive than Franklin Rods scheme; also some non-critical facilities may be at risk due to possibility of direct strikes. Whereas, DAS System tries to avoid strikes, the franklin Rods attempts to channel nearby strike to earth.

\subsection{Surge Protection evaluation Schemes}

The following surge protection schemes could be deployed in petroleum industry, overhead transmission and distribution circuits:

(a) Lightning Arrestors on transformer primary and secondary connections: This involves the installation of properly rated lighting metal oxide surge arrestors on the primary connections of all $11 \mathrm{KV}$ distribution transformers, and also on the transformer secondary side at the electrical service entrances of all major sensitive electronic equipment facilities like the control or communications buildings. The scheme provides primary surge protection of transformers; and diverts most large surges originating on the power system due to lightning or switching actions. The limitations of the scheme include (i) Inability to protect sensitive electronic equipment from local side generated transients. (ii) Failure to completely eliminate power system generated surges from travelling downstream. (iii) Needs to be coordinated with downstream surge suppression devices.

(b) Surge suppression on panel board outgoing feeders from panel board: In this arrangement, suitably rated metal oxide low voltage surge arrestors are installed on the outgoing panel board feeders supplying major electronic load equipment or facilities. The scheme is capable of diverting residual of utility system generated surges not mitigated by upstream lightning arrestors, need only to be applied where building or facilities wiring is not required to handle large surge duty. Its disadvantages include: (i) Inability to completely protect sensitive electronic equipment from transients generated at the board connection point or within the facility. (ii) Requires additional panel board space. (iii) Requires additional maintenance inspection and testing to verify integrity. (iv) Needs to be coordinated with upstream and downstream surge protective devices.

(c) Surge suppression units at each sensitive load input/output or receptacle: It involves the installation of combination of varistor and transorb low voltage Transient Voltage Surge Suppressor (TVSS) units at each connection point of sensitive electronic equipment. The schemes advantages include: the ability to divert surge generated within the premises that is very close to the internal surge source or sensitive equipment; and can be combined with individual uninterruptible power supplies (UPS) for personal computers, printers, video display terminals, etc. While its limitation is that all inputs and outputs such as power, communications and control and UPS connections need to have surge protection installed.

(d) Building Power Distribution /Clean Room: The scheme is based on the installation of power distribution units (PDU) or computer power centre (CPC) as the principle means of supplying the power and earthing interface between the premises' electrical supply system and connected sensitive electronic equipment. The PDUs may contain simply an isolating transformer or line voltage regulating transformer up to and including full UPS capacity, It has the following advantages:

(i) Allows for the separation and isolation of transient sensitive loads (such as computers, communications equipment control equipment, video display terminals) from transient producing equipment (photocopiers, air conditioners electronic or discharge lighting circuits).(ii) Readily incorporated into new building or premise designs.

(ii) It can be a prefabricated $\mathrm{AC}$ power and earthing package.

(iii) It can be incorporated with a common UPS system.

(iv) Provides for more flexible wiring methods. Its disadvantages include: more difficult to retrofit into an existing building`s power distribution systems; requires doubling up on building or room power distribution into "clean" and "dirty" Supplies; and diligence required not to mix- up transient generating and transient sensitive loads.

(e) Combination of $\mathbf{a}, \mathrm{b}$, $\mathbf{c}$ and $\mathbf{d}$ surge protection systems: It involves application of $\mathrm{a}, \mathrm{b}, \mathrm{c}$, and d protection schemes as appropriate. Appling lighting arrestors on transformer high voltage connections primarily to protect the transformer, but

WWW.scirj.org

(C) 2020, Scientific Research Journal

http://dx.doi.org/10.31364/SCIRJ/v8.i12.2020.P1220832

This publication is licensed under Creative Commons Attribution CC BY. 
also to lessen the downstream surge suppression requirements for lightning and switched disturbances originating back in the power system. It concerns the provision of "clean" PDS/UPS power to each system (such as process control, fire/gas and safeguarding and telecommunication systems); and transorb low voltage transient voltage surge suppressor (TVSS) devices on panel board supply feeders. TVSS devices should be provided on panel board feeders supplying sensitive electronic loads (such as personal computers and other low voltage sensitive users); and individual UPS/surge suppression units should be provided at each location. The main advantage of this scheme is that it allows for graded surge suppression devices commensurate with surge duty expected on equipment or facilities at risk. Surge protection needs to be fully coordinated from high voltage power system to end user connection point hence constitute its disadvantage.

\section{Conclusion}

Based on past history, the existing lightning protection has not been very effective in protecting the petrochemical facilities from lightning strikes. Among all the lightning protections considered, the combination of Charge Transfer Technology or DAS and Franklin Rods is chosen as an effective lightning protection system to be installed in the petroleum industry for all tanks, buildings and facilities. DAS system reputed for: successful installations avoiding strikes; successful avoidance of secondary effects such as bound charge and earth currents; avoidance of control and communication outages. The DAS system tries to avoid lightning strikes, while the Franklin Rods try to absorb the strike when it occurs close to area of coverage and channel it to earth.

In addition to the installation of lightning protection, all main power, control and communication feeders to the facility and office complexes should be protected by the coordinated installation of lightning arrestors, transient voltage surge suppressors (TVSS) as well as Power Distribution Supplies (PDS) /Uninterrupted Power Supplies (UPS) units for major facilities such as the control and communication centre.

This paper therefore proposes the deployment of combination of surge protection (scheme e) for the protection of power, control and communication circuits.

\section{Conflict of Interest}

The authors declare no conflict of interest.
[3] R.B. Carpenter Jr. and M.N. Drabkin. Lightning Strike Protection, Lightning Eliminators and Consultants, Inc., 6687 Arapahoe Road, Boulder, Colorado 80303, USA, PP.1-30, 1990.

http://www.lightningeliminators.com Assessed 24th July, 2020.

[4] A.J. Welker, "Lightning - Its effects and some simple safeguards in regards to oilfield operations", Proceeding of Annual Southwestern Petroleum Short Course, pp 329-346, 1998.

[5] Global Lightning Technologies "The formation of lightning." http://www.glt.com/technology/formation.Assessed 27th October, 2018.

[6] R.B. Carpenter Jr., Lightning Protection for Flammables Storage Facilities, Lightning Eliminators and Consultants, Inc, Boulder, Colorado, USA, PP.112,1990 .

[7] O. I. Elgerd, Electrical Energy Systems Theory: Anlntroduction, $2^{\text {nd }}$ edition, McGraw- Hill lnc., New York, pp. 364, 1971.

[8] B. R. Gupta, Power System Analysis and Design, $4^{\text {th }}$ edition, S. Chand and Company Ltd, New Delhi, pp. 381-402, 2006.

[9] V. K. Mehta, and R.Mehta, Principles of Power System, $18^{\text {th }}$ edition, S. Chand and Company Ltd, New Delhi, pp. 555-567, 2004.

[10] Global Lightning Technologies. "Comparison of Design Methods forLightning Protection"

http://www.glt.com/technology/dsgnmeth.htm. Assessed 27th October, 2018

[11] Global Lightning Technologies, "Earth Grid Design." http://www.glt.com/earthing/ erthgrid.htm. Assessed 26th October, 2018.

[12] H.F.G.Gwyther, Solving Problems in Electrical Power and Power Electronics, John Wiley and Sons, N- York, pp. 132, 1983.

[13] C.A.Gross, Power System Analysis, 2nd edition, John Wiley and sons, NYork, pp 120, 1979.

[14] F. Progress, The Design of the Electrical Services for Buildings, 3rd edition, Chapman and Hall, London, pp. 234, 1989.

[15] E. N. C.Okafor, D. C.Idoniboyeobi and I. O.Akwukwaegbu, Effective Surge Protection Practice for Low Voltage Installation of Electric Circuits, Journal of Economics and Engineering, ISSN: 2078-0346, no. 4, pp. 63-68, 2010.

[16] E. N. C. Okafor, D. C.Idoniboyeobi and I. O. Akwukwaegbu, Surge Protection Practice for Equipment in Substations, International Journal of Academic Research, vol. 3, no.1, pp. 25-31, 2011.

[17] I. J. Nagrath and B. P.Kithara, Power System Engineering, Tenth edition, Tata-McGraw-Hill, pp. 592-593, 1994.

\section{References}

[1] H. Persson and A. Lönnermark, Tank Fires, Review of Fire Incidents 19512003, Brandforsk Project 513-021.

[2] Large Atmospheric Tank Fires (LASTFIRE), Project Analysis of Incident Frequency Survey, June 1997.

WWW.scirj.org

(C) 2020, Scientific Research Journal

http://dx.doi.org/10.31364/SCIRJ/v8.i12.2020.P1220832

This publication is licensed under Creative Commons Attribution CC BY. 